\title{
Quero um caixãozinho: a morte de crianças em contos de Mia Couto e Guimarães Rosa
}

\author{
I want a little coffin: the death of children \\ in Mia Couto and Guimarães Rosa short stories
}

\author{
MARCOS APARECIDO PEREIRA ${ }^{1}$ \\ EPAMINONDAS DE MATOS MAGALHÃES (Dי ${ }^{1}$ \\ MARINEI ALMEIDA (1) 2 \\ ${ }^{1}$ IFMT, Cárceres, Mato Grosso, Brasil. \\ 2UNEMAT, Cárceres, Mato Grosso, Brasil.
}

\begin{abstract}
Resumo: Este trabalho apresenta a análise comparada dos contos $A$ menina de lá, de Guimarães Rosa e O rio das Quatro Luzes, de Mia Couto que giram em torno de uma mesma temática. Ambos mostram a morte sob a perspectiva de uma criança, apresentando facetas surpreendentemente interessantes para os leitores, por meio de construções miméticas que fazem fantasiar e refletir sobre as maneiras como lidamos com o fim. Assim, no trabalho que se segue buscaremos avaliar os elementos que permeiam a vida e o inesperado desejo de morte de um menino e de uma menina em dois contextos distintos. São narrativas que levam o leitor a ponderar de que forma a morte pode ser poética, ainda que acometendo crianças. Além disso, o leitor é impelido ao aprofundamento de suas próprias experiências relacionadas à temática e convidado a aprimorar sua compreensão do mundo infantil e da morte. Desta forma, nos contos dos dois autores temos a possibilidade de perceber a morte sob o olhar de duas crianças em diferentes contextos e perspectivas sociais. E a partir dessas construções traçar algumas reflexões a respeito da morte, sua representação e a maneira como é encarada pelas personagens infantis nas narrativas.
\end{abstract}

Palavras-chave: crianças; morte; experiências; reflexões.

\begin{abstract}
This article shows the comparative analysis of the tales A menina de lá (The girl from there), by Guimarães Rosa and O rio das Quatro Luzes (The River of the Four Lights), by Mia Couto that revolve around the same theme. Both show death from the perspective of a child, presenting facets surprisingly interesting to readers, through mimetic constructions that make them fantasize and reflect about how we dead with the end. Thus, in this work, we will seek to evaluate the elements that permeate the life and the unexpected death wish of a boy and a girl in two different contexts. These are narratives that lead the reader to consider how death can be poetic, even though it affects children. In addition, the readers are encouraged to deepen their own experiences related to the theme and they are invited to enhance their understanding of the children's world children and of death.
\end{abstract}

Keywords: children; death; experiences; thoughts. 


\section{Introdução}

Neste trabalho buscamos analisar comparativamente a morte em dois contos: A menina de lá, presente no livro Primeiras Estórias, de Guimarães Rosa e $O$ rio das Quatro Luzes, do livro A menina sem palavra, de Mia Couto. Além disso, fundamentados na Teoria do Imaginário, de Gilbert Durand, procuramos compreender como os personagens lidam com a certeza e a proximidade do ponto final da vida.

Considerado um dos maiores escritores brasileiros de todos os tempos, Guimarães Rosa ambienta quase todas suas histórias no sertão brasileiro. A maior parte dos estudos relacionados à obra desse autor versa sobre as inovações no uso da linguagem marcada pela influência da fala popular regional e pela criação de inúmeros vocábulos sob as mais variadas técnicas. Entretanto, a contribuição deste escritor para a compreensão do ser humano em sua própria essência é sem dúvida ímpar, pois, a literatura oferece-nos representações reveladora do homem e de sua realidade (LLOSA, 2016).

Mia Couto é um premiado escritor moçambicano cuja obra tem sido referência na literatura de língua portuguesa. Sua produção conta com poemas, contos, crônicos e romances que expõem a tradição e a memória cultural do povo africano tanto escrevendo para adultos quanto para crianças. Bastante relacionado a Guimarães Rosa pelo seu estilo de incorporação de vocábulos populares à literatura, as narrativas de Couto articulam o local e o universal (MACÊDO; MAQUÊA, 2008).

Ambos os autores foram capazes de debruçar-se sobre a temática pouco explorada da morte de crianças nas narrativas ficcionais oferecendo-nos reflexões acerca do modo como os pequenos encaram o assunto. Cada um com a sua perspectiva, tanto o brasileiro quanto o moçambicano são capazes de expor uma temática tão delicada e cheia de mistérios de uma forma singela, porém carregada de reflexões temperadas pelo realismo fantástico. Um realismo que tem muito a ver com a morte, que nos apresenta a cada dia sua face real e, ao mesmo tempo, permeada de fantasia, seja ela na esperança da vida pós-morte ou no encontro com um ser encapuzado de túnica negra (símbolo bastante difundido para representar a morte). Isto posto e fundamentados em Durand (1994) é possível afirmar que a morte carrega uma ambiguidade fundamentada no real e no imaginário, no fim e no começo, no certo e incerto.

Pode-se dizer, ainda, que nada é mais certo e universal que a morte, ao mesmo tempo em que nada é mais incerto que o que vem após a morte. Esse é um drama legitimamente humano e a maneira como cada cultura e cada indivíduo lida com a certeza do fim é bastante peculiar. Entretanto, é fato que as culturas criam símbolos para enfrentar a morte e a passagem do tempo (DURAND, 2004). Logo, ao tratar da percepção da criança com relação a morte, os contos dão-nos a chance de refletir sobre nossa própria visão acerca da temática enquanto vivenciamos a experiência humanizadora ofertada pela ficção literária (CANDIDO, 2011).

\section{Quero um caixãozinho: a morte de crianças em contos de Mia Couto e Guimarães Rosa}

Segundo Coutinho (2013, p.42) "as crianças de Primeiras Estórias são seres 
especiais, dotadas de uma sensibilidade que os adultos não possuem". São narrativas curtas, cuja base é, no geral, "decifrar o mistério da vida e o sentido da existência humana" (ibidem). Enquanto isso, sumariamente, em $A$ menina sem palavra, as crianças, mostram-nos a complexidade das famílias, da sociedade e dos enfrentamentos infantis ao descobrir o mundo. Em ambos os casos a dança entre razão e misticismo (ou saberes míticos populares) dão o tom surreal das narrativas e levam-nos ao estranhamento e à reflexão. E, talvez nada seja mais real e mítico que a morte, com suas definições e suas representações em cada estrutura cultural, pois, de acordo com Durand (2004), o homem tenta fugir simbolicamente da morte e da passagem do tempo criando formas de enfrentar esses fenômenos que atormenta a sua existência.

A morte é, geralmente, um assunto delicado, carregado de sentimentos múltiplos, sobretudo quando se trata de morte de criança. O falecimento infantil sempre comove, pois, a princípio, foge da ordem natural, interrompe o curso da história de uma vida que, em suma, deixa de existir de forma precoce. O próprio Mia Couto no conto O não desaparecimento de Maria Sobrinha, comenta: "nunca se encontrou nada mais triste que caixão pequenino" (COUTO, 2013, p. 81). Talvez por isso poucos autores se propõem a pensar a temática da morte neste viés. Ainda assim, Guimarães Rosa e Mia Couto lançam-se neste desafio e, cada um à sua maneira usa da temática no processo de construção literária que nos leva, em primeiro lugar, à saciação da necessidade vital e universal que o homem tem de fantasiar, de sonhar (CANDIDO, 1999, 2011); e, em segundo lugar, ao processo de autoconhecimento, uma vez que a "a literatura satisfaz [...] a necessidade de conhecer os próprios sentimentos e a sociedade, ajudando-nos a tomar posição em face deles" (CANDIDO, 2011, p. 182, 183). Isso porque, de acordo com Llosa (2016):

A ficção não reproduz a vida; ela a nega, utilizando-se de um truque que finge substituí-la. Mas também, de uma maneira sempre difícil de estabelecer, a completa, acrescentando à experiência humana algo que os homens não encontram em suas vidas reais, somente naquelas, imaginárias, que vivem indiretamente, graças a ficção. (LLOSA, 2016, p. 36, tradução nossa).

Portanto, ao debruçarmo-nos sobre as vidas e mortes dos personagens mimética e simbolicamente representados nos contos temos a chance de olharmos para dentro de nós mesmos amplificando a percepção sobre nós e sobre o mundo que nos rodeia, ao mesmo tempo em que encaramos o fenômeno inalterável da passagem do tempo que nos leva à finitude (DURAND, 2004).

Kovács (1992) explica que desde muito cedo experimentamos as experiências de morte. Segundo a autora, nossa primeira experiência de morte é a experimentação da ausência da mãe, fato que deixa marcas em nossa formação e desenvolvimento; em seguida outras experiências de "perda" e morte nos são apresentadas, desde a morte de um inseto até a morte de um animal querido ou de uma pessoa próxima.

Apesar da morte fazer parte do desenvolvimento humano, normalmente, não desejamos a morte. O homem há muitos séculos "desafia e tenta vencer a morte" (KOVÁCS, 1992, p. 02). Afinal, comumente, ela "representa o desconhecido e mal" (KOVÁCS, 1992, p. 04). Por isso Durand 
(2004) explica que o homem cria maneiras simbólicas de encarar a morte e a certeza da finitude. Contudo, nas duas crianças apresentadas nos contos a que propusemos analisar, há o desejo de morte. Um desejo que nas duas narrativas é inicializado (ou corporificado) por um caixão. O que nos leva a algumas perguntas preliminares: o que levaria uma criança a desejar a morte? Que tipo de encantamento um caixão poderia gerar em uma criança para que ela desejasse morrer?

Em O rio das Quatro Luzes, logo no início do conto, o menino, personagem principal, fala: "Mãe: eu também quero ir em caixa daquelas" (COUTO, 2013, p.129). Como era de se esperar a mãe ralha com a criança, apavora-se, rompe em prantos e pede a ajuda do pai. Entretanto, ambos não conseguem dissuadir a ideia do menino que inveja o morto e toda a atenção dada a ele durante o funeral. A fascinação é tanta que o garoto se pergunta: "Ter alguém assim que chore por nós, quanto vale uma tristeza dessas?" (COUTO, 2013, p. 129).

Enquanto isso, Nhinhinha, a criança do conto $A$ menina de lá não é ouvida pelos pais quando expressa seu fúnebre desejo, quem a ouve é Tiantônia. Numa manhã de arco-íris "sobressaído em verde e vermelho - que era mais um vivo corde-rosa" (ROSA, 2005, p.68), a menina alegrou-se como nunca se havia visto até então, tanto que os pais perguntaram-se: "Adivinhou passarinho verde?" (ROSA, 2005, p.68). Foi em meio a tanta alegria que Tiantônia ouvira que ela queria um "caixãozinho cor-de-rosa, com enfeites verdes brilhantes..." (ROSA, 2005, p.69). Instantaneamente repreendeu a menina, mas não revelou o fato aos pais. A criança, calou-se, aquietou-se, mas mantinha "seu passarinho-verde no pensamento" (ROSA, 2005, p. 68).

Em ambos os casos, primeiramente, percebemos e eufemização da morte pela visão das crianças (DURAND, 2004). Em seguida, o oposto caracterizado pelo choque dos adultos quando as crianças falam que desejam um caixão. Um assombro que, talvez por não saber lidar com o assunto, leva à repreensão dos pequenos. Outra hipótese está relacionada com a pouca compreensão que os adultos acreditam que as crianças têm do mundo, da vida e, portanto, da morte. Além disso, ao não falar sobre a morte com as crianças muitos adultos pensam estar protegendo a criança das dores da realidade (KOVÁCS, 1992). Por um motivo ou por outro, no conto de Rosa, a tia nem tenta conversar com a menina, já na narrativa de Couto há a tentativa de diálogo acerca do assunto, primeiro com o pai e, em seguida, com o avô que, segundo o pensamento acertado do garoto, the "escutaria com maiores paciências" (COUTO, 2013, p. 130). Entre a visão das crianças e dos adultos sobre a morte temos uma dança entre os Regimes Diurnos e Noturnos descritos por Durand (2004). Enquanto os adultos tentam vencer e/ou negar a morte e o devir, as crianças dos contos a identificam como natural e/ou reconciliadora.

Neste último, a relação entre avô e neto é que vai marcar o traçado da história. A exemplo de outras criações literárias do mesmo autor, a articulação entre o velho e novo, o moderno e a tradição, o conhecimento e a inexperiência é que faz a roda das narrativas ficcionais girar e encantar. Isso sem contar que, de acordo com Macêdo e Maquêa (2008), temáticas como a morte e o encontro possível entre as duas margens da existência (vida e 
morte) são fortemente marcadas na escrita de Mia Couto.

Outro ponto de destaque nos trechos comentados anteriormente é que as crianças não abandonam o desejo por causa da repreensão dos adultos, o menino "calou-se, guardado em si" (COUTO, 2013, p. 129) enquanto a menina, também quieta, manteve no pensamento "seu passarinhoverde" (ROSA, 2005, p. 68). Expressão esta que carrega a cor da esperança e que é empregada para aqueles que demonstram alegria, o que sugere que a expectativa da realização daquele desejo dava-lhe grande contentamento.

Ainda podemos destacar que nos dois contos as crianças possuem escassez de comunicação e afeição com os mais velhos, o menino só consegue interação com o avô, enquanto que a menina parece realizar sua maior interação com o narrador, no quinto parágrafo, logo após, mencionar que Nhinhinha gostava dele. E como, anteriormente, o próprio narrador diz que ela "nem parecia gostar ou desgostar especialmente de coisa ou pessoa nenhuma" (ROSA, 2005, p.65), é possível suspeitar que foi, assim como no caso do menino, a atenção paciente dada à ela que fez nascer esta identificação eles.

As crianças dos dois contos carregam diferenças, mas também semelhanças e apresentam o caráter universal presente na representação artística. Nhinhinha, Maria de nome, é filha de sitiantes de um lugarejo atrás Serra do Mim, vive com o pai, mãe e a tia. Já do menino sem nome próprio do outro conto, pouco sabemos. Temos conhecimento que vive apenas com o pai e a mãe, mas que o avô mora nas cercanias. A falta das especificações acerca do menino é proposital, pois é comum que nas narrativas de Couto haja um duplo movimento de regionalização e universalização (MACÊDO; MAQUÊA 2008) dos dramas dos personagens. O menino é um menino moçambicano ao mesmo tempo em que é um menino global, pois a imitação artística da realidade (mimese) tem base no possível e no verossímil e, devido a isso, possibilita a universalização de fatos e de ações dos personagens (ARISTÓTELES, 2010). O mesmo pode ser dito da menina, pois, segundo Coutinho (2013, p. 27): “os heróis de Guimarães Rosa [são] tipos no sentido de que expressam seu caráter coletivo [...], mas transcendem sua tipicidade pela dimensão humana de que são dotados".

A protagonista Nhinhinha, por exemplo, nasce miúda e frágil, tanto que diminutivo dobrado de seu nome ressalta esta fragilidade. Ela não quer brinquedo nenhum, permanece a maior parte do tempo sem se mexer e fala de maneira incompreensível. "Seria um tanto tolinha?" (ROSA, 2005, p.68), pergunta o narrador frente à comunicação sem nexo da menina, indicando, de forma eufêmica, que ela poderia ter nascido com algum nível de retardo mental.

Entretanto, no parágrafo seguinte ele deixa-nos uma dúvida, que não vem em forma de pergunta, mas que paira no conto, inicialmente, sob a formação de uma palavra "suasibilíssima". Segundo Rocha (1988, p.100) "da aglutinação de suave mais sibila mais -íssima surgiu a forma 'suasibilíssima'", ou seja, o narrador refere-se a menina como uma profetisa suavíssima. Seria um tanto sábia? - nos questionamos. Isto talvez explicasse a falta de interesse por coisas que outras pessoas "normais" pudessem interessar ou pensassem que interessaria à uma criança de quatros. 
Por outro lado, o menino descrito por Couto tem o raciocínio lógico perfeito, não aparenta qualquer problema físico, porém carrega traços de depressão. Faltava-Ihe atenção, conforme pode ser constatado no momento em que sente inveja da tristeza empregada ao morto. Além disso, em outro trecho notamos que "nunca o pai lhe dirigira um pensamento" (COUTO, 2013, p. 129). Isso sem contar na conversa que o avô tem com os pais da criança após constatar os motivos que tinham levado o menino a desejar envelhecer rápido e, consequentemente, morrer. Segundo o avô, "faltava aos pais serem filhos, juntarem-se miúdos com o miúdo" (COUTO, 2013, p.131), ou seja, dar ao filho a atenção que uma criança precisa.

A ausência da família, o isolamento como indivíduo-criança na família, a sensação de ser (estar) deslocado no mundo, levaram-no ao desejo de morte, possivelmente com o propósito de chamar a atenção, de encontrar o seu lugar na existência e apagar o sentimento de nãopertencimento. "Que valia ser criança se Ihe faltava a infância?", pergunta o narrador no conto de Mia Couto (2013, p.130). E já que "sem infância, o ser humano seria natureza inerte" (KOHAN, 2007, p. 113), o garoto sentia-se um nada. Provavelmente por isso ele queria desistir de tudo e não gostava dessa "prenda" chamada vida: "[...] ele não gostava dessa prenda. Não seria que Deus Ihe podia dar outra diferente?" (COUTO, 2013, p.130). Dessa forma, a morte parece ao menino muito mais sedutora e cheia de oportunidades que a vida, a oportunidade de mudança e/ou recomeço.

Ao seguir o caminho rumo ao único mal irremediável, como diria Chicó
(SUASSUNA, 2005), ambas as crianças passam por experiências mágicas e/ou fantásticas. "O fantástico seria o irreal no sentido estético daquilo que é apenas imaginável; o que não é visível aos olhos de todos, que não existe para todos, mas que é criado pela imaginação, pela fantasia de um espírito" (HELD, 1980, p. 25).

A menina Nhinhinha, por exemplo, começou, de repente, a fazer milagres, tudo o que deseja se tornava, subitamente, realidade. Mas, devido ao raciocínio pouco desenvolvido ou por causa da óptica diferenciada que tinha do mundo, ela desejava apenas coisas simples e com o único interesse de satisfazer pequenas vontades ou emoções, por mais que, várias vezes os pais tenham tentado tirar "o sensato proveito" (ROSA, 2005, p.68) daqueles poderes sobrenaturais. A pequena desejou ver um sapo e também comer pãezinhos de goiabada, acabou curando a mãe "sem querer", quis avistar um arco-íris e seu último desejo foi o tal caixãozinho cor-de-rosa. E como para a menina "a palavra é carregada de magia, o querer identifica-se com o realizar-se" (SIMÕES, 1988, p. 77), todos seus desejos se tornaram reais.

Já o menino é, primeiramente, tomado pelas experiências fascinantes da infância que, até então, não tivera a oportunidade de estrear. $\mathrm{O}$ avô promete que falará com Deus a fim de que ele o neto troquem de lugar quando a hora da morte chegar. Animado com a possibilidade, o garoto passa a frequentar ativamente a casa do avô que, por sua vez, aproveita para iniciar o neto "nos amplos territórios da infância" (COUTO, 2013, p.131), adentrando em grutas e rios, caçando insetos e desvendando pistas de animais na mata. 
A arte de morrer é substituída pela arte de viver, os cuidados relativos à morte são transferidos para a vida, para cada dia desta vida. Não se trata, porém, de uma vida qualquer: a preparação para a morte exige que toda a vida seja impregnada de morte (ARIÉS, 1983, p. 54).

Assim, antes desta troca de experiências entre as duas fases da vida (velhice e infância) representadas pelos personagens, avô e neto têm "idades" trocadas, enquanto o neto, cansado da vida, quer encontrar a morte, o avô, encantado com a existência, ensina-nos a "desobedecer ao tempo, esquivar-se do corpo e do juízo" (COUTO, 2013, p.131). A proximidade com a morte, impulsiona, muitas vezes, a viver e desfrutar a vida em sua plenitude, como no caso dos personagens descritos. Ao longo dos acontecimentos poderíamos dizer que ambos acabam saboreando a infância, já que, de acordo com Kohan (2007, p. 99), “infância também tem a ver com revisitar certos lugares como se fosse a primeira vez". E também, de acordo com o fragmento do parágrafo anterior, realizando os preparativos para a morte.

A segunda experiência mágica (ou inexplicável) ocorrida na narrativa do menino foi no instante da morte do avô:

[...] Olhando o rio, lá em baixo. E ali ficou, em silêncio. De repente, ele viu a corrente do rio inverter de direcção.

- Viram? O rio já se virou.

E sorriu. Estivesse confirmando o improvável vaticínio. O velho cedeu às pálpebras. Seu sono ficou sem peso. Antes, ainda murmurou no ouvido de seu filho:

- Diga a meu neto que eu menti. Nunca fiz pedido nenhum a nenhum Deus.

Não houve precisão de mensagem. Longe, na residência do casal, o menino sentiu reverter-se o caudal do tempo [...] (COUTO, 2013, p. 132, grifos do autor).
No mesmo instante em que o avô via a correnteza do rio mudar de direção, à distância, o neto sentia, também, o fluxo do tempo mudar de direção e ser entregue novamente ao seu antigo possuidor (reverter-se), ou seja, a vida é correlacionada na narrativa com o rio e com o próprio tempo. Outra possibilidade de interpretação é pensar que, para aquele que morre, o tempo volta - da velhice à infância - e quem expira por último é a segunda.

Percebemos, também, no excerto anterior que o avô tinha consciência da iminência da própria daqueles acontecimentos. Um pouco antes ele relata que estava mais "celestial que nuvem" e que estava sendo chamado. Além disso, temos a confissão-pedido feita ao filho e, ainda, a constatação de que o rio já havia se virado. O uso do advérbio já indica que ele sabia que a inversão da correnteza do rio aconteceria. Aliás, o próprio narrador reforça esse fato quando se refere a um vaticínio, profecia, que não se pode provar. Isto posto e se tomarmos como base que a correnteza do rio simboliza o fluxo da vida e seu tempo, percebemos que o velho estava indicando que a vida estava mudando de direção e voltando para o lugar misterioso de onde um dia saiu. Um retorno que, talvez, jamais possamos provar (improvável).

Outro ponto interessante de ser observado em ambos os contos é a alegria dos personagens que precede a morte. No caso do menino, "na companhia do avô, o moço se criançava, convertido em menino. A voz antiga era o pátio onde ele se adornava de folguedos" (COUTO, 2013, p.131), ou seja, finalmente havia encontrado a alegria de ser criança e divertia-se. Já na outra narrativa, da menina 
descrita por Guimarães Rosa, temos a passagem do passarinho-verde na qual a jovem estava alegre além do normal. Em ambos os casos é possível compreender que ter desejo atendido, ou a perspectiva desse atendimento é que alegra a vida das crianças nos dois contos, afinal tanto o menino quanto Nhinhinha não eram contentes antes de "saber" que iam morrer.

No que se refere ao menino, a confiança na proposta do avô fez, talvez, tenha feito com que ele se soltasse para a vida e passasse a enxergar com outros olhos as aventuras propostas. O que não sabemos é se essa nova perspectiva da vida o fez em algum momento mudar de ideia com relação ao desejo de morte. O temos consciência é que o garoto acreditava que Deus daria deferimento no pedido de toca das mortes. Por outro lado, com relação a menina, é possível que o arcoíris, assim como na passagem bíblica pósdilúvio, seja identificado como a promessa de Deus. Neste caso, a promessa de voltar para Deus, para o paraíso, para o além, ou simplesmente para "lá", como deixa explícito o título, visto que, Nhinhinha não é uma criança daqui, da terra, ela é $A$ menina de lá. Assim, possivelmente, Nhinhinha em sua sobrenaturalidade já sabia disso, bastava-Ihe a confirmação que veio com o arco-íris. Outro fato que corrobora com a hipótese são as seguintes passagens em que a pequena menina já dá sinais de que ia morrer ou que desejava partir: "Outra hora, falava-se de parentes já mortos, ela riu: - 'Vou visitar eles...'" (ROSA, 2005, p.66, grifo do autor) e também: "Eu quero ir lá.' - Aonde? - 'Não sei'." (ibidem). $\mathrm{E}$, talvez mais sutilmente, a cor da roupa que a menina usava quando disse isso, amarelo, ou seja, atenção.
$\mathrm{E}$, finalmente, chegamos ao momento da morte nos dois contos. A menina morre "da má água desses ares" (ROSA, 2005, p.68) e é tida pela mãe ao final da narrativa como uma milagreira, Santa Nhinhinha. Ainda é possível observar que as cores do caixão enfeitado solicitado pela pequena indicam que para a personagem a morte se apresenta cor-de-rosa, ou seja, romântica, terna e mais: adornada de esperança, insinuado pelos "enfeites verdes brilhantes" (ROSA, 2005, p. 69).

Enquanto isso, no outro conto, os olhos do menino se santificam e vão para o leito do rio. "E os seus olhos se intemporaram em duas pedrinhas. No leito do rio se afundaram quatro luzências" (COUTO, 2013, p. 132). Avô e neto unem-se, tal qual vinham fazendo em suas aventuras, desta vez no fundo do rio da vida, purificados em forma de quatro luzes. Luzes essas que dão nome ao rio e que dão título ao conto. Acreditamos ser palpável, por fim, relacionar o título do conto com as quatro fases da vida do nascimento até a morte: infância, juventude, maturidade e velhice. Assim, cada etapa da vida seria uma pedrinha com brilho próprio nas águas da vida.

\section{Considerações}

Em ambos os contos percebemos que para as crianças a morte não tem uma conotação ruim, carregada de sofrimento e perda. Poderíamos dizer que em ambos os casos é possível constatar um processo de eufemização da finitude, como diria Durand (2004). As cores que circundam a morte, as luzes, a alegria e finalmente o encontro com o fim são em ambos os contos leves, suaves e até tenros. Também é possível notar que há uma certa inversão 
no senso comum: a morte parece bem mais atrativa que a vida para as crianças personagens de Rosa e Couto.

Nhinhinha encara a morte com naturalidade, como um retorno a um lugar do qual realmente se pertence, permeada de esperança transcendental sobrenatural. A visão do conto de Mia Couto é bem parecida, entretanto, o menino tem mais esperança no recomeço de uma nova vida, sem os problemas da atual existência.

Contudo, nesse último texto, tanto menino quanto avô servem para a construção de uma alegoria que mostra o mérito de cada uma das fases da vida e de como elas se juntam e voltam ao "lugar de origem" no final da vida. Tendo a morte como um recomeço ou não, o que não é claro na visão do conto, o destaque acaba ficando por conta da importância da vida em cada uma de suas etapas e na reflexão possível que pode ser extraída de Guimarães Rosa em Grande Sertão: Veredas quando diz que o real não nos é apresentado nem na partida e nem na chegada e sim no meio da travessia, ou seja, é o caminho percorrido que mais importa.

Assim, tanto Rosa quanto Couto tecem os contos com um realismo fantástico que convida o leitor a duas experiências: a reflexão sobre o enfrentamento da realidade, por vezes amarga, da vida, com seus problemas e desalentos e, também, do encantamento e/ou da admiração de eventos que são possíveis apenas nas bem amarradas e reveladoras (LLOSA, 2016) linhas da ficção literária. Arte ficcional que, por sua vez, é capaz de realizar a mediação entre o eterno e o temporal na constante busca pelo equilíbrio das pulsões e tensões do próprio homem e do mundo (DURAND, 1994), guiando-nos à humanização disponibilizada pela literatura (CANDIDO, 2011).

\section{Referências}

ARIÈS, Philippe. O homem diante da morte. Rio de Janeiro: F. Alves, 1983.

ARISTÓTELES. Arte poética. São Paulo: Martin Claret, 2010.

CANDIDO, Antonio. A literatura e a formação do homem. Remate de Males, Campinas, p. 81-90, 1999. Disponível em: https:// periodicos.sbu.unicamp.br/ojs/index.php/ remate/article/view/8635992. Acesso em: 09 abr. 2019.

CANDIDO, Antonio. Vários escritos. 5. ed. Rio de Janeiro: Ouro Sobre Azul, 2011.

COUTINHO, Eduardo F. Grande Sertão: Veredas: travessias. São Paulo: É Realizações, 2013. (Biblioteca Textos Fundamentais).

COUTO, Mia. O rio das quatro luzes. In: COUTO, Mia. A menina sem palavra: histórias de Mia Couto. São Paulo: Boa Companhia, 2013. https://doi.org/10.21165/el.v46i3.1630

DURAND, Gilbert. A imaginação simbólica. Lisboa: Edições 70, 1994.

DURAND, Gilbert. As estruturas antropológicas do imaginário. São Paulo: Martins Fontes, 2014.

HELD, Jacqueline. O imaginário no poder: as crianças e a literatura fantástica. São Paulo: Summus, 1980.

KOHAN, Walter O. Infância, estrangeiridade e ignorância: ensaios de filosofia e educação. Belo Horizonte: Autêntica, 2007.

KOVÁCS, Maria Júlia. Morte e desenvolvimento humano. São Paulo: Casa do Psicólogo, 1992.

LLOSA, Mario Vargas. La verdad de las mentiras. São Paulo: Alfaguara, 2016.

MACÊDO, Tânia; MAQUÊA, Vera. Literaturas de língua portuguesa: marcas e marcos: Moçambique. São Paulo: Arte \& Ciência, 2008. 
ROCHA, Maria Miquelina Barra. A magia das palavras. Caligrama, Belo Horizonte, v. 1, p. 99-110, out. 1988. Disponível em: http:// www.periodicos.letras.ufmg.br/index.php/ caligrama/article/view/146/97. Acesso em: 04 jan. 2019.

ROSA, João Guimarães. Grande Sertão:

Veredas. Rio de Janeiro: Nova Aguilar, 1994.

ROSA, João Guimarães. A menina de lá. In: ROSA, João Guimarães. Primeiras estórias. Rio de Janeiro: Nova Fronteira, 2005. https://doi. org/10.11606/d.8.2011.tde-21062012-164503

SIMÕES, Irene Gilberto. Guimarães Rosa: as paragens mágicas. São Paulo: Perspectiva, 1988.

SUASSUNA, Ariano. Auto da Compadecida. 35. ed. Rio de Janeiro: Agir, 2005.

Recebido em: 23/01/2019

Aceito em: 01/02/2019

Publicado em: 00/05/2019

\section{Autores:}

MARCOS APARECIDO PEREIRA

Doutorando em Estudos Literários do PPGEL da Universidade do Estado de Mato Grosso (Unemat); Professor do IFMT Campus Cáceres - Prof. Olegário Baldo.

Orcid: https://orcid.org/0000-0001-9498-8248

e-maiL: marcos.pereira@cas.ifmt.edu.br

EPAMINONDAS DE MATOS MAGALHÃES

Doutorado em Letras pela Pontifícia Universidade Católica do Rio Grande do Sul, Professor do IFMT Campus Pontes e Lacerda Fronteira Oeste.

Orcid: https://orcid.org/0000-0002-6070-219X

e-mail: epaminondas.magalhaes@plc.ifmt.edu.br

MARINEI ALMEIDA

Doutorado em Letras pela Universidade de São Paulo; professora da Universidade do Estado de Mato Grosso (Unemat).

Orcid: https://orcid.org/0000-0001-7255-3956

e-mail: marinei.almeida@unemat.br 